\title{
Adolescents' food habits and nutritional status in urban and rural areas in Cameroon, Africa'
}

\author{
Léonie Nzefa Dapi', Christophe Nouedoui ${ }^{2}$, Urban Janlert' and \\ Lena Håglin ${ }^{3}$
}

\author{
'Umeå International School of Public Health, Umeå University, Umeå, Sweden; ${ }^{2}$ Faculty of Medicine and Biomedical \\ Sciences, University of Yaoundé I, Yaoundé, Cameroon; ${ }^{3}$ Department of Family Medicine, University Hospital, Umeå, \\ Sweden
}

Abstract

Background: Food intake in Cameroon is based on three meals daily. The diet in rural areas is based on traditional staple foods, while that of the urban population incorporates more modern foods. The health and nutrition of adolescents is important as their eating behaviour and nutrition will affect their future health. Objective: To describe and compare food habits and nutritional status of adolescents in Cameroon. Design: A cross-sectional study using an unquantified food frequency questionnaire and anthropometric data, in urban and rural areas. Fifty-two adolescents, 12-15 years old, were selected from schools. Results: Frequencies of consumption of meat, vegetables, cereals, milk products and junk food were significantly higher in urban than in rural adolescents ( 11.8 vs $4.5,9.5$ vs $3.9,16.5$ vs $11.9,5.7$ vs $0.8,24.2$ vs 8.7, respectively). The frequency of in-between meals was higher in urban than in rural adolescents (4.9 vs 0.9 , respectively). Arm muscle area $\left(\mathrm{AMA}, \mathrm{mm}^{2}\right)$ and waist/hip ratio were significantly higher in rural than in urban adolescents (3554 vs 2802 and 0.82 vs 0.79 , respectively). Body mass index (BMI, $\mathrm{kg} \mathrm{m}^{-2}$ ) was higher in rural than urban adolescents, although not significant (20.6 vs 19.4 , respectively). There was a positive significant correlation between BMI and AMA in urban and rural areas ( $r=0.67$ and $r=0.72$, respectively). Conclusions: Despite a lower frequency of food consumption, rural adolescents had higher AMA and waist/ hip ratio than urban adolescents. Less junk food and more traditional food consumption, more manual activities and walking in rural adolescents could explain these results.

Keywords: Adolescents; arm muscle area; body mass index; Cameroon; food frequency; waist/hip

Received: 26 Jun. 2005; Revised: 12 Oct. 2005; Accepted: 26 Oct. 2005

\section{Introduction}

Food intake in Cameroon is based on three main meals daily. The meal is composed of cereals or roots with sauce from green leaves, oil and meat/fish depending on the economic situation of the household (1-3). In rural areas, people eat the same type of dishes based on traditional staple foods, whereas the urban population incorporates more modern foods into the diet $(1,2,4,5)$. In urban areas in Cameroon, as in other countries in Africa, a lot of food is consumed outdoors, mostly on the streets, which is not the case in rural areas $(1,2,4,6-8)$. Food sold on the street by vendors is mostly composed of junk food $(2,4,6-8)$.

Adolescence (age 10-19 years) is one of the most challenging periods in human development (9).
Physical and psychological changes are taking place and many important issues arise that influence the nutritional well-being of adolescents $(10,11)$. Eating behaviours that are learned early in life are maintained in adulthood (9-11). Nutritional inadequacies influence not only adolescents' health but also the risk for major chronic diseases in adulthood (12).

Adolescents constitute $23.7 \%$ of the Cameroonian population (13). A focus on the health and nutrition of this group warrants particular attention, since these young people are the future generation of the country. Moreover, type 2 diabetes mellitus, hypertension, obesity, deficiencies and anaemia are partly related to food habits and are prevalent in Cameroon (1, 3-5). 
No study so far has dealt with food habits and nutrition among adolescents in Cameroon. The present study was carried out to describe and compare the food habits and nutritional status of adolescents in urban and rural areas in Cameroon.

\section{Methods and subjects}

\section{Study design, sampling and subjects}

This cross-sectional study was carried out in an urban and a rural area in Cameroon. The study comprised 52 boys and girls, 12-15 years old, selected from the second grade in public secondary schools. One school was randomly selected in the Yaoundé urban area. In the Bandja rural area the only school was selected. For the rural area all adolescents in the class who were present at the time of the study were included ( $n=26,12$ boys and 14 girls); the same number of adolescents was randomly selected from the school in the urban area ( $n=26,13$ boys and 13 girls). The mean age among the adolescents was 12.7 years in the urban and 13.7 years in the rural areas.

\section{Settings}

Yaoundé, the capital of Cameroon, is located in the centre province with a population of 1.4 million inhabitants (3). Bandja is a village located in the western province, with 8000 inhabitants. The primary occupation of the people of Bandja is farming, while in Yaoundé mostly white-collar workers and entrepreneurs prevail.

The timetable in both urban and rural schools is from 07.30 to $15.15 \mathrm{~h}$, with one 15 min break at 10.30 and one 30 min break at 12.45. School is held on Monday to Friday, with Wednesday afternoons free (14). There are no restaurants or canteens in public schools in Cameroon.

\section{Data collection}

Data were collected by the first author, two school nurses and two medical students. The school nurses and the medical students had been trained in collecting data.

A general questionnaire was used for background data, a food frequency questionnaire (FFQ) collected data on food and meal frequencies, and anthropometric data were obtained to describe nutritional status. The questionnaires had been tested among a group of adolescents of the same age who were selected from another school. The questions were adjusted according to the experience obtained.

Instructions were given by the first author and the school nurses to the adolescents before and while they were filling in the questionnaires. Questionnaires were filled in during breaks and school lessons. All questionnaire data was checked and verified by the first author. Data were collected from September to October 2004, a period that corresponds to the beginning of the first term of school in Cameroon. The language used for this study was French.

The study variables were chosen according to the aim of the study and based on studies about adolescents $(10,15,16)$.

\section{General questionnaire}

A general questionnaire was used to collect information about geographical area, date of birth, gender, mode of transport, amount of pocket money, bringing food from home or buying it in school, leisure-time activity, household chores, home equipment, and availability of water and electricity sources in the household.

\section{Unquantified food frequency questionnaire}

The FFQ is a cheap and useful tool to describe and assess the food pattern over recent months $(9,11$, $12,15)$. The FFQ was developed by the fist author and two nutritionists, based on instructions from nutritional surveys $(10,15)$, an FFQ used to assess food habits in Cameroon (17), and a questionnaire from the World Health Organization (WHO) Health Behaviour in School-aged Children study (HBSC/WHO, 1997-1998) (18).

Focus group interviews with adolescents (not the study participants), parents, teachers, school nurses and vendors were used to obtain information about the most consumed food to be included in the FFQ. The FFQ consisted of 54 food items, including wheat bread, milk, butter, beans (Vigna uncuiculata), wheat doughnuts, plantain (Musa paradisiaca), cassava (Manihot dulcis), maize (Zea mays), maize porridge, groundnuts (Arachis hypogaea), yam (Dioscorea spp.), unripe banana stew (Musa sapientum), traditional cakes (pounded maize mixed with green leaves), okok (Gnetum spp.), safou (Dacroydes edulis), meet/fish/eggs, fruits, rice, candies, pastry and soft drinks, subdivided into eight groups (cereals, roots/plan- 
tain, vegetables/green leaves, fruit, meat/fish/ eggs, pulses/nuts/beans, milk products and junk food) (19).

Frequencies of breakfast, lunch, dinner and inbetween meals were also collected. Junk food comprised sandwiches (white or sweet bread with chocolate, butter, sweet milk and mayonnaise), biscuits, chocolate, candies, groundnuts, okok (green leaves with groundnuts, palm oil and sugar), chips, sweet beverages, cake and doughnuts. Breakfast was the meal eaten between 06.00 and $10.00 \mathrm{~h}$, lunch between 12.00 and $14.00 \mathrm{~h}$ and dinner after $16.00 \mathrm{~h}$. All food items consumed between the main meals were classified as in-between meals.

The FFQ was self-reported, by asking adolescents how many times a day and how many times per week they consumed each of the food items listed. No specified quantities were recorded; therefore, collected data were only used for assessing the frequency of food or meals. There were six dropouts from the FFQ in the rural area owing to sickness, a lack of school fees and change of school, but none in the urban area.

\section{Anthropometry}

Body weight $(\mathrm{kg})$ was registered using a Seca model 862 scale and height $(\mathrm{cm})$ using a stadiometer (Seca) made from a tape-measure fixed to the wall and a headpiece equipped with a level to ensure a right angle. Body weight and height were measured in the morning, with subjects dressed in light clothes without shoes, by the school nurses and the medical students. Subcutaneous fat (mm) (triceps, biceps, subscapular and suprailiac skinfold thickness) was measured by the first author using a calliper (John Bull British). Triceps and biceps skinfolds were measured on the right arm, suprailiac skinfold was measured at a level immediately above the iliac crests, and the subscapular skinfold was obtained below the inferior scapular angle (10). Waist circumference $(\mathrm{cm})$, hip circumference $(\mathrm{cm})$ and mid-upper arm circumference (MUAC) $(\mathrm{cm})$ were measured by the first author using a tapemeasure.

To standardize the measurements and practices, each interviewer measured and weighed some adolescents who did not participate in the present study. The skinfold thicknesses were measured twice and the mean value was calculated. All the measurements were performed at school.
Waist/hip ratio, body mass index (BMI, $\mathrm{kg} \mathrm{m}^{-2}$ ) and arm muscle area (AMA, $\mathrm{mm}^{2}$ ) were calculated. AMA was calculated by using a formula involving triceps skinfold and MUAC (10) (see footnote to Table 3).

BMI is an inexpensive, quick and reliable screening tool used to assess nutritional status in adults, children and adolescents $(10,15,16)$. However, one drawback of BMI is that high muscle mass can yield high BMIs even though body fat is not excessive $(15,16)$. Therefore, to obtain complete information about adolescents' actual body composition, this study also used skinfold and circumference measurements, which are relevant and inexpensive screening tools used to assess nutritional status in growing children and adolescents $(10,15,16)$.

\section{Statistical analysis}

Analyses were performed using SPSS version 11. Data analysis included descriptive statistics of the respondents. Means, standard deviations, percentages and correlations were computed. Food and meals frequencies, and anthropometric variables were normally distributed. Differences were analysed using Student's $t$-test and univariate anova adjusted for age and gender. Differences were considered statistically significant when the $p$-value was less than 0.05 .

AMA and the body weight for height and age of the participants were compared with a reference population $(10,20)$.

\section{Ethical considerations}

Permission to carry out this study was obtained from the Ministry of High Education of Cameroon, the medical school board of the Ministry of Public Health, local authorities and headmasters of schools before the study. In addition, approval permission and written consent were obtained from all study participants.

\section{Results}

\section{General questionnaire}

Urban adolescents described their activities as watching television, listening to music, sleeping, resting, cleaning and washing. They had televisions, telephones, stoves, tap or well water and electricity at the household level, and they went to school by car or by motorcycle taxi. In contrast, rural 
adolescents described their activities as farming, carrying water, dishing, sweeping, washing, cooking and playing football. They had no cars, televisions, electricity, stoves, tap or well water supplies at the household level, and they walked a long distance to school during weekdays and to farms during weekends.

One urban adolescent, compared with four rural adolescents, received no daily pocket money. Eight urban adolescents, compared with 15 rural, received 25-150 Franc CFA (1 Euro $\approx 656$ FCFA). Seventeen urban adolescents, compared with seven rural, received 200 Franc CFA or more.

In the urban area three out of 26 adolescents and in the rural area four out of 26 brought their lunch from home to school.

\section{Frequency of food and meals reported}

There were significant differences in food frequencies between urban and rural adolescents for all food groups, with the exceptions of fruit, roots/ plantain and beans/pulses/nuts (Table 1). Milk products (sweet milk, powdered milk, yoghurt), vegetables/green leaves, cereals, meat/fish/eggs (beef, chicken, pork, goat, fish) and junk food were significantly more often consumed by urban than by rural adolescents.

The frequency of in-between meals was significantly higher among urban than rural adolescents. Breakfast and lunch were slightly different between urban and rural adolescents, although this difference was not significant (Table 2).

\section{Anthropometry}

The anthropometric characteristics of the adolescents are presented in Table 3. There were signifi- cant differences between urban and rural adolescents for age, AMA and waist/hip ratio. BMI, MUAC and total skinfold were also different, although not significantly so.

A higher proportion of urban adolescents were below US reference standards for AMA and above the WHO reference for body weight for height (Table 4).

There was a significant positive correlation between BMI and AMA in both urban and rural areas (Fig. 1). There was no correlation between AMA and waist/hip ratio in either rural or urban areas.

\section{Discussion}

\section{Food habits and meals patterns}

Cameroon is a country with clear lifestyle differences between urban and rural people (1-5). The difference are becoming increasingly obvious nowadays compared with the past (1). Influences from the lifestyle on food habits and meals patterns are indicated in the present study.

There was a higher frequency of junk food consumption among urban than rural adolescents. In the urban area, food is readily available in a variety of settings and sold by a multitude of vendors in school yards. Food from vendors is cheap and consists mostly of junk food. Adolescents in the urban area were therefore accustomed to buying junk food from vendors during break times, at lunch and in-between meals. In contrast, there are occasionally a few vendors within the school yard in the rural area, which may have contributed to the lower frequency of junk food consumption among rural adolescents. Findings from previous studies indicate that consumption of junk food was

Table I. Reported frequency per week of eight food groups

\begin{tabular}{|c|c|c|c|c|c|}
\hline \multirow[b]{2}{*}{ Food group } & \multicolumn{2}{|c|}{ Urban $(n=26)$} & \multicolumn{2}{|c|}{ Rural $(n=20)$} & \multirow[b]{2}{*}{$P$-Value } \\
\hline & Mean $\pm S D$ & $\%$ of total food intake & Mean $\pm S D$ & $\%$ of total food intake & \\
\hline Fruit & $11 \pm 5.2$ & 10.6 & $8.9 \pm 4.4$ & 13.1 & 0.165 \\
\hline Milk products & $5.7 \pm 3.4$ & 5.5 & $0.8 \pm 1.7$ & 1.4 & $<0.001$ \\
\hline Beans/pulses/nuts & $7.6 \pm 4.3$ & 7.3 & $9.3 \pm 3.3$ & 15.3 & 0.288 \\
\hline Vegetables/green leaves & $9.5 \pm 3.7$ & 9.1 & $3.9 \pm 2.4$ & 6.7 & $<0.001$ \\
\hline Meat/fish/eggs & $11.8 \pm 5.2$ & 11.3 & $4.5 \pm 2.9$ & 8.0 & $<0.001$ \\
\hline Cereals & $16.5 \pm 5.1$ & 15.9 & $11.9 \pm 5.3$ & 20.1 & 0.040 \\
\hline Roots/plantain & $17.9 \pm 8.1$ & 17.2 & $13.1 \pm 7.0$ & 21.4 & 0.386 \\
\hline Junk food & $24.2 \pm 1.8$ & 23.2 & $8.7 \pm 3.9$ & 14.2 & 0.009 \\
\hline
\end{tabular}

$P$-Values for the differences between urban and rural pupils/adolescents were adjusted for age and gender. 


\begin{tabular}{|c|c|c|c|c|c|}
\hline \multirow[b]{2}{*}{ Meal } & \multicolumn{2}{|c|}{ Urban pupils $(n=26)$} & \multicolumn{2}{|c|}{ Rural pupils $(n=20)$} & \multirow[b]{2}{*}{$P$-Value } \\
\hline & Mean \pm SD & $\%$ of total meal intake & Mean \pm SD & $\%$ of total meal intake & \\
\hline Breakfast & $5.0 \pm 2.3$ & 22.6 & $6.7 \pm 1.1$ & 34.9 & 0.217 \\
\hline Lunch & $6.1 \pm 2.1$ & 26.9 & $5.0 \pm 2.1$ & 26.0 & 0.203 \\
\hline In-between meal & $4.9 \pm 2.3$ & 21.9 & $0.9 \pm 1.4$ & 4.7 & $<0.001$ \\
\hline Dinner & $6.5 \pm 1.7$ & 28.6 & $6.6 \pm 1.6$ & 34.4 & 0.784 \\
\hline
\end{tabular}

$P$-Values for the differences between urban and rural pupils/adolescents were adjusted for age and gender.

high in urban areas $(2,6-8,21)$. In Tunisia and Benin (Africa), candies, sandwiches, pastries and sweet beverages were most often consumed by schoolchildren $(6,8,21)$. Snack foods and sweet beverages were frequently consumed among Chilean and Greek adolescents $(11,12)$.

In the present study, as in other studies carried out in Africa, it was common for urban and some rural adolescents to receive daily pocket money from their parents to buy food at school (6-8, 21). The high frequencies of junk food and inbetween meals in urban adolescents could also be due to the fact that they had more pocket money than rural adolescents. Some adolescents in the

Table 3. Anthropometric characteristics of urban and rural adolescents

\begin{tabular}{lcll}
\hline Characteristic & Urban $(n=26)$ & Rural $(n=26)$ & $p$-Value \\
\hline Age (years) & $12.7 \pm 0.7$ & $13.7 \pm 1.1$ & 0.001 \\
Weight $(\mathrm{kg})$ & $45.3 \pm 8.5$ & $47.9 \pm 8.1$ & 0.453 \\
Height $(\mathrm{cm})$ & $152.2 \pm 9.3$ & $152.9 \pm 8.4$ & 0.171 \\
BMI $\left(\mathrm{kg} \mathrm{m}^{-2}\right)$ & $19.4 \pm 2.1$ & $20.6 \pm 2.3$ & 0.096 \\
AMA (mm $\left.{ }^{2}\right)$ & $2802 \pm 474$ & $3554 \pm 614$ & 0.044 \\
MUAC (cm) & $21.9 \pm 2.3$ & $24.1 \pm 2.1$ & 0.180 \\
TSF (mm) & $10.1 \pm 4.8$ & $9.8 \pm 3.2$ & 0.463 \\
BSF (mm) & $7.3 \pm 2.5$ & $6.3 \pm 2.5$ & 0.175 \\
SSSF (mm) & $8.8 \pm 3.0$ & $9.1 \pm 2.9$ & 0.712 \\
SISF (mm) & $6.9 \pm 2.5$ & $6.8 \pm 2.4$ & 0.164 \\
Total skinfold (mm) & $33.1 \pm 11.6$ & $31.9 \pm 9.8$ & 0.447 \\
Waist (cm) & $66.00 \pm 5.6$ & $70.34 \pm 4.7$ & 0.108 \\
Hip (cm) & $82.7 \pm 6.8$ & $85.2 \pm 6.2$ & 0.329 \\
Waist/hip & $0.79 \pm 0.03$ & $0.82 \pm 0.04$ & 0.001
\end{tabular}

Data are given as mean $\pm S D$.

$p$-Values for the differences (except for age) between urban and rural adolescents were adjusted for age and gender.

BMI: body mass index; AMA: arm muscle area; MUAC: mid-upper arm circumference; TSF: triceps skinfold thickness; BSF: biceps skinfold thickness; SSSF: subscapular skinfold thickness; SISF: suprailiac skinfold thickness.

$\mathrm{AMA}=(\mathrm{MUAC}-\pi \times \mathrm{TSF})^{2} / 4 \times \pi$; correction factors: -10 for males and -6.5 for females (I0). rural area did not eat at school owing to a lack of pocket money. A study carried out in Africa shows that pupils from families with higher economic status consumed more junk food than adolescents from families with lower economic status $(8,21)$.

Few adolescents brought lunch from home to school; therefore, almost all adolescents, especially in the urban area, bought their lunch at school. The same results have been described in Benin and Mali (Africa) $(4,21)$.

The fact that there is no school restaurant and too little time to go home for lunch can explain to some extent why adolescents were accustomed to eating junk food and in-between meals. Similar results were shown by other studies (6-8).

There was a difference between urban and rural adolescents in milk consumption. In the urban area, milk products are available and affordable, and are consumed during breakfast as a drink with sugar and bread, whereas in the rural area breakfast is composed of leftover traditional food. In contrast to the urban area, milk products are expensive, less available and not considered as a "food" in the rural area. Meat/fish/eggs are more available and affordable in the urban areas, while in the rural areas they are eaten on special occasions owing to high prices and low availability.

Vegetables/green leaves are consumed in both areas, but are more processed in the urban area than in the rural area. The high frequency of cereals in urban adolescents may be due to the high consumption of wheat bread. The same result has been described previously $(6,11)$.

Differences in food habits between urban and rural adolescents can be explained by the nutritional transition from a traditional to modern/Western 
Table 4. Distribution of arm muscle area (AMA) and body weight of urban $(n=26)$ and rural $(n=26)$ adolescents below or above reference standards

\begin{tabular}{|c|c|c|c|c|c|c|c|c|}
\hline \multirow{3}{*}{$\begin{array}{l}\text { Age } \\
\text { (years) }\end{array}$} & \multicolumn{4}{|l|}{ AMA } & \multicolumn{4}{|c|}{ Body weight } \\
\hline & \multicolumn{2}{|c|}{$<25$ th percentile } & \multicolumn{2}{|c|}{$>75$ th percentile } & \multicolumn{2}{|l|}{ Below } & \multicolumn{2}{|l|}{ Above } \\
\hline & Urban & Rural & Urban & Rural & Urban & Rural & Urban & Rural \\
\hline 12 & $7 / 11$ (64) & $0 / 5(0)$ & I/II (9) & I/5 (20) & I/II (9) & $0 / 5(0)$ & $6 / 11(55)$ & $\mathrm{I} / 5(20)$ \\
\hline 13 & $6 / 11(55)$ & I/6 (17) & $0 / 11(0)$ & $1 / 6(17)$ & I/II (9) & $0 / 6(0)$ & $5 / 11(45)$ & $1 / 6(17)$ \\
\hline 14 & $2 / 4(50)$ & I/7 (14) & $0 / 4(0)$ & 2/7 (29) & I/4 (25) & I/7 (14) & $2 / 4(50)$ & $2 / 7(29)$ \\
\hline 15 & - & $2 / 8(25)$ & - & $2 / 8(25)$ & - & $1 / 8(13)$ & - & $2 / 8(25)$ \\
\hline
\end{tabular}

Data are given as the number and percentage (\%) of adolescents with AMA for age and gender below the 25th and above the 75th percentiles from US population references (10), and for body weight for height, age and gender below and above World Health Organization references (20).

lifestyle in Cameroon and other African countries $(1,4-8,21)$.

\section{Nutritional status}

The differences between the modern and traditional way of living in urban and rural areas may have an impact on the nutritional status of adolescents. Rural adolescents had a higher AMA, probably because of daily manual activities and walking, whereas urban adolescents undertook fewer manual activities and walking owing to modernization, such as having cars, available water sources, televisions and stoves at the household level.
The difference between urban and rural regarding the food system could also have an impact on the nutritional status of adolescents. In the rural area, the food system is characterized by self-subsistence food from farming, breeding, hunting, picking and gathering, with little purchased food. In contrast, in the urban area, food is mostly purchased and people are used to consuming industrial, imported and canned food products.

The higher BMI (although not significant) in rural adolescents may also be due to more physical activities resulting in more muscle, as confirmed by a strong positive relationship between AMA and BMI.

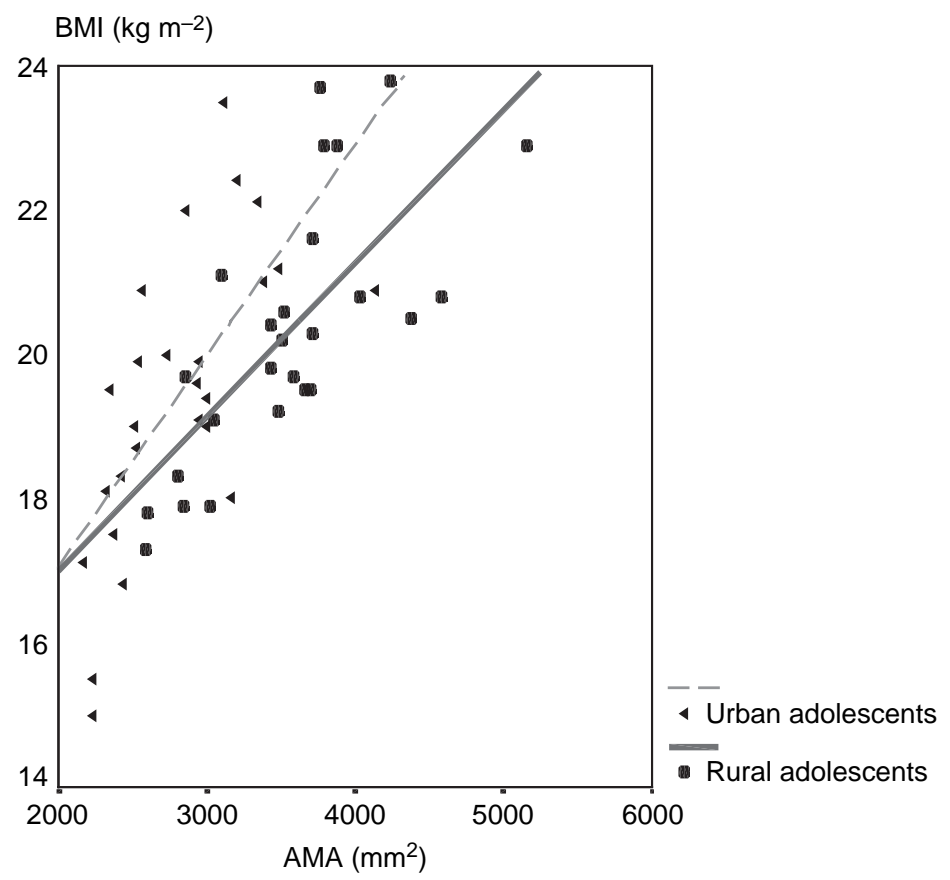

Fig. 1. Correlation between body mass index (BMI) and arm muscle area (AMA) among urban $(r=0.67, p<0.001)$ and rural $(r=0.72, p<$ 0.001 ) adolescents. 


\section{Strengths and weaknesses of the study}

The present study is the first carried out in Cameroon to describe the food habits and nutritional status among adolescents. Therefore, the methods and results developed would be useful as basic information in further studies among adolescents. The present study had several strengths, including a sociodemographic sample (rural, urban), a validated, comprehensive measure of food habits and accurate anthropometric measurements. In addition, the results have been adjusted for gender and age.

The smaller sample size and cross-sectional design are weaknesses of the present study. A followup design with a larger sample size should be considered in further studies. Selection bias may be a potential weakness, since the present study is based on adolescents involved in school. Therefore, the results should be generalized with caution. Puberty, characterized by physical changes in the body, may be a potential confounding factor for the present study since it is related to adolescents' anthropometrics and food consumption. Thus, puberty should be considered in further studies.

\section{Conclusion}

In the urban area in Cameroon, adolescents ate more junk food, had a higher amount of pocket money, and were engaged in fewer manual activities and walking than adolescents in the rural area. The food habits in rural adolescents were characterized by traditional food, and despite a lower frequency of meat/fish/eggs, vegetables, cereals and milk products, AMA, BMI and waist/ hip ratio were higher in rural than in urban adolescents.

\section{Acknowledgements}

This study was supported by a scholarship from Västerbotten County Council and the Kempe Foundation of Umeå, Sweden, and a scholarship from the Ministry of High Education of Cameroon.

\section{References}

1. Aperçu Nutritionnel du Cameroun, ENS, FAO, Division de la Nutrition. Base de données FAOStat sur les bilans alimentaires. Available from URL: http://www.fao.org/ giews/french/basedocs/cmr/cmrcon4f.stm. Accessed 5 February 2004.

2. Mennen LI, Mbanya JC, Cade J, Balkau B, Sharma S, Chungong S, Cruickshank JK. The habitual diet in rural and urban Cameroon. Eur J Clin Nutr 2000; 54: $150-4$.

3. Cameroun, Enquête Nationale sur la Carence en Vitamine A et l'Anémie. Cameroon: Ministère de la Santé Publique; September 2001.

4. Mbanya JCN, Minkoulou EM, Salah NJ, Bakau B. The prevalence of hypertension in rural and urban Cameroon. Int J Epidemiol 1998; 27(2 Suppl): 181-5.

5. Sobngwi E, Mbanya J-CN, Unwin NC, Kengne AP, Fezeu L, Minkoulou EM, et al. Physical activity and its relationship with obesity, hypertension and diabetes in urban and rural Cameroon. Int J Epidemiol 2002; 26: 1009-16.

6. Chauliac M, Bricas N, Atego E, Amoussa W, Zohoun I. L'alimentation hors du domicile des écoliers de Cotonou (Bénin). Cahier Santé 1998; 8: 101-8.

7. Bendech MA, Chauliac M, Gerbouin Rérolle P, Kanté $\mathrm{N}$, Malvy DJM. Les enjeux de la consommation alimentaire en milieu urbain à Bamako. Santé Publique 2000; 12(1 Suppl): 45-63.

8. Neffati L, Ridha $H$, Kolsteren $P$, Hilderbrand $K$. L'alimentation de rue chez l'écolier dans une région $\mathrm{du}$ nord de la Tunisie. Cahier Santé 2004; 14: 43-8.

9. Nana Lien. Stability and predictors of eating behaviors during adolescence and early adulthood. In: Doctoral thesis. Oslo: University of Oslo; 2002.

10. Mahan LK, Arlin M. Krause's food nutrition and diet therapy, 8th edn. Philadelphia, PA: Saunders; 1992.

11. Oliveres S, Kain J, Lera L, Pizarro F, Vio F, Moron C. Nutritional status, food consumption and physical activity among Chilean school children: a descriptive study. Eur J Clin Nutr 2004; 58: 1278-85.

12. Yannakoulia M, Karayiannis D, Terzidou M, Kokkevi A, Sidossis LS. Nutrition-related habits of Greek adolescents. Eur J Clin Nutr 2004; 58: 580-6.

13. Cameroon pyramid. Source: US Census Bureau, international database. Available from URL: http:// www.census.gov/cgi-bin/ipc/idbagg. Accessed 15 September 2005.

14. Ministère de l' Education Nationale, Délégation Provinciale de l' Ouest, Délégation Départementale du Haut-Nkam. CES Bilingue de Bandja; 2003.

15. Margetts BM, Nelson M. Design concepts in nutritional epidemiology, 2nd edn. Oxford: Oxford University Press; 1998.

16. Witt KA, Bush EA. College athletes with an elevated body mass index often have a high upper arm muscle area, but not elevated triceps and subscapular skin folds. J Am Diet Assoc 2005; 105 (4 Suppl): 599-602.

17. Sharma S, Cade J, Jackson M, Mbanya JC, Chungong S, Forrester $\mathrm{T}$, et al. Development of food frequency questionnaires in three population samples of African origin from Cameroon, Jamaica and Caribbean migrants to the UK. Eur J Clin Nutr 1996; 50: 479-86.

18. HBSC/World Health Organization. Health Behaviour in School-aged Children: a World Health Organization 
collaborative cross-national study. HBSC protocol for 2001/02 survey. Geneva: WHO; 1997-98.

19. Ngo Som J, Abondo A. Les ressources alimentaires du Cameroun: répartition ecologique, classification et valeur nutritive; 1989.

20. World Health Organization (WHO). Energy and protein requirements. Report of a joint FAO/WHO/UNU expert consultation. Technical report series 724. Geneva: WHO; 1985.

21. Chauliac M, Monnier T, Bendech MA. Bamako school age children and their diet from street vendors. Cahier Santé 1994; 4: 413-23.

\section{Léonie Dapi Nzefa}

Umeå International School of Public Health Department of Public Health and Clinical Medicine

Epidemiology and Public Health Sciences

Umeå University

SE-90। 85

Umeå

Sweden

Tel: +467852732

Fax: +4690138977

E-mail: leonie.dapi.nzefa@epiph.umu.se 